\title{
Influência do ambiente térmico no comportamento e desempenho zootécnico de suínos
}

\author{
Influence of the thermal environment on the behavior and performance of pigs
}

\section{Tatiany Carvalho dos Santos ${ }^{1 *}$, Cinara da Cunha Siqueira Carvalho ${ }^{2}$, Geruza Cardoso da Silva ${ }^{2}$, Thamara Amaral Diniz ${ }^{2}$, Thaís Emanuele Soares ${ }^{2}$, Sóstenes de Jesus Magalhães Moreira² \& Paulo Roberto Cecon ${ }^{1}$}

${ }^{1}$ Universidade Federal de Viçosa, Viçosa, MG, Brasil. *Autor para correspondência: taty17_carvalho@hotmail.com.

${ }^{2}$ Universidade Estadual de Montes Claros, Janaúba, MG, Brasil.

\section{Submissão:30/04/2017 | Aceite: 09/05/2018}

\begin{abstract}
RESUMO
Os modificadores ambientais, como o uso da lâmina d'água, são frequentemente utilizados na produção de suínos, com intuito de melhorar as condições de bem-estar e consequentemente, a produção. Diante dessa consideração, buscou-se avaliar o efeito do ambiente climático sobre o ganho de peso e o comportamento de suínos em fase de terminação em baias com e sem acesso à lâmina d'água. $O$ trabalho foi conduzido em uma granja suinícola localizada na cidade de Nova Porteirinha, localizada na região semiárida de Minas Gerais. Para avaliar o conforto térmico dos animais utilizou-se o Índice de Temperatura de Globo Negro e Umidade (ITGU) e para análise do comportamento dos suínos observouse o número de animais realizando a atividade, por período avaliado, bem como, o ganho de peso. No terceiro bloco os valores de índice de temperatura de globo negro e umidade foram maiores havendo menor ganho de peso médio diário. Os tratamentos resultam em diferentes respostas comportamentais, sendo o comportamento na lâmina d'água mais expressivo no período da tarde. O período de avaliação mostrou influenciar na temperatura superficial e em temperaturas elevadas os animais apresentam menor ganho de peso médio diário. A lâmina d'água não influenciou no ganho de peso dos animais, entretanto, proporcionou melhores condições de bem-estar.
\end{abstract}

PALAVRAS-CHAVE: ambiência, bem-estar, ganho de peso, lâmina d'água, suinocultura.

\begin{abstract}
Environmental modifiers, such as the use of water blade, are often used to produce pigs in order to improve welfare conditions and consequently production. In view of this consideration, we sought to evaluate the effect of the climatic environment on the weight gain and the behavior of pigs in the finishing phase in stalls with and without access to the water blade. The work was conducted in a pig farm located in the city of Nova Porteirinha, located in the semi-arid region of Minas Gerais. In order to evaluate the thermal comfort of the animals, the Black Globe Temperature and Humidity Index (BGHI) was used to evaluate the thermal comfort of the animals and to analyze the behavior of the pigs, the number of animals performing the activity, for the period evaluated, as well as the gain of weight were observed. In the 3rd block, black globe temperature and humidity index values were higher, with lower average daily weight gain. The treatments resulted in different behavioral responses, with water blade behavior being more expressive in the afternoon. The evaluation period showed that to influence surface temperature and at high temperatures the animals presented lower daily average weight gain. The water table did not influence the animals' weight gain, however, it provided better welfare conditions.
\end{abstract}

KEYWORDS: ambience, animal welfare, thermal comfort, pig farming.

\section{INTRODUÇÃO}

A suinocultura brasileira, a exemplo de outras cadeias produtivas do agronegócio, cresceu significativamente nos últimos anos. Esse crescimento é notado quando se analisa os vários indicadores econômicos e sociais, como volume de exportações, participação no mercado mundial, número de empregos diretos e indiretos, entre outros (GONÇALVES \& PALMEIRA 2006). Entretanto, em virtude das exigências ao atendimento às questões de bem-estar animal, torna-se necessária a utilização de 
equipamentos ou ações para a manutenção de um ambiente mais homogêneo e propício para o bom desenvolvimento e desempenho dos animais, principalmente em regiões com elevadas temperaturas, onde há uma constante ocorrência de situações de estresse térmico (SALES et al. 2011).

$O$ estresse térmico, resultante de altas temperaturas ambientais pode afetar negativamente as reações fisiológicas e comportamentais dos animais e até mesmo o consumo de ração dos mesmos. Segundo SOUZA et al. (2010), a elevada temperatura ambiental, a umidade do ar e a radiação solar direta são os principais responsáveis por causarem o desconforto fisiológico que leva os animais a adotarem medidas fisiológicas e comportamentais para manter a homeotermia, e que na maior parte das vezes culminam com a redução no desempenho produtivo.

De acordo com PANDORFI et al. (2008) o suíno apresenta dificuldade para dissipar calor em ambiente de alta temperatura e umidade, pois o excesso de umidade restringe as perdas evaporativas pela respiração e contribui para diminuir o apetite. Os suínos apresentam glândulas sudoríparas afuncionais, queratinizadas e para realizar a manutenção de sua temperatura corporal, desta forma torna-se necessário fornecer aos animais alternativas para a realização de trocas de calor, como por exemplo aumentando o contato corporal com a superfície e por meio de trocas evaporativas (RODRIGUES et al. 2010). A presença da lâmina d'água nas baias possibilita que os animais troquem calor por processos sensíveis. Os suínos, quando confinados e sob estresse térmico tendem a se espojar sobre suas próprias fezes e urina na tentativa de perder calor (CARVALHO et al. 2004).

A fim de diminuir os efeitos do ambiente térmico sobre os suínos, várias alternativas são comumente adotadas, como a utilização de modificadores ambientais, dentre eles a utilização de lâminas d'água. O uso da lâmina d'água em baias de crescimento e terminação auxilia na adaptação dos animais expostos as altas temperaturas, e consequentemente mantém a atividade fisiológica dentro de parâmetros normais (BERTON 2013). Neste sentido, o objetivo foi avaliar o efeito do ambiente térmico sobre o ganho de peso e o comportamento de suínos em fase de terminação em baias construídas com e sem acesso à lâmina d'água.

\section{MATERIAL E MÉTODOS}

\section{Local}

O trabalho foi desenvolvido na Granja Araújo, localizada no município de Nova Porteirinha, MG, onde a latitude é de $15^{\circ} 47^{\prime} 50^{\prime \prime} \mathrm{S}$ e longitude $43^{\circ} 18^{\prime} 31^{\prime \prime}$ W e altitude de $516 \mathrm{~m}$, e clima, segundo Köppen, do tipo AW (tropical chuvoso, savana com inverno seco). A coleta dos dados experimentais ocorreu no período de agosto a novembro de 2013, compreendendo a fase de crescimento e terminação dos suínos.

\section{Animais utilizados e manejo}

Foram utilizados 40 suínos híbridos, machos castrados e fêmeas, da linhagem comercial (reprodutor LM $6200 \times$ matriz DB 90), com idade média de 65 dias e peso vivo médio de $25 \mathrm{~kg}$, com densidade populacional de 20 animais baia ${ }^{-1}$. Os animais foram alojados em duas baias situadas em um galpão de alvenaria com cobertura de telha de barro, com piso de concreto. As baias onde os animais ficaram acomodados possuem $8 \mathrm{~m}^{2}(2,0 \times 4,0 \mathrm{~m})$, equipadas cada uma com um bebedouro e comedouro semiautomático, posicionado na parede divisória das baias, de forma a atender as duas áreas.

O fornecimento de ração e água aos animais foi realizado de forma ad libitum. Foram utilizados bebedouros automáticos do tipo "nipple" e comedouros semi-automáticos, mantendo-os sempre abastecidos. A ração fornecida aos animais foi baseada para atender as exigências nutricionais de suínos na fase de crescimento e terminação.

\section{Tratamentos}

O experimento foi dividido em 2 tratamentos da seguinte forma:

- Tratamento 1: 20 animais acomodados em baia com piso de concreto e com lâmina d'água $(0,80 \mathrm{~m}$ de largura e $\pm 10 \mathrm{~cm}$ de profundidade), sendo 0 abastecimento e troca de água realizado com 0 uso de mangueira, duas vezes por semana.

- Tratamento 2: 20 animais alojados em baia com piso de concreto e sem lâmina d'água, onde a limpeza era efetuada duas vezes por semana.

\section{Caracterização do ambiente térmico}

O ambiente térmico foi caracterizado por meio da coleta de temperatura do ar (Tar), umidade relativa do ar (UR), temperatura de ponto de orvalho (Tpo), e temperatura do globo negro (Tgn) a cada hora, com início às 7:30 $\mathrm{h}$ e término às 17:30 $\mathrm{h}$. Para isto foram utilizados 2 datallogers, sendo 1 datalloger no interior da instalação, na altura dos animais, e 1 no exterior da instalação (modelo RTH 10, Extech ${ }^{\circledR}$, BOSTON, EUA), que armazena a temperatura em uma faixa de medição entre $-40^{\circ} \mathrm{C} \mathrm{a}+70^{\circ} \mathrm{C}$, umidade relativa entre 0 a $100 \%$, temperatura de ponto de orvalho entre $-40{ }^{\circ} \mathrm{C} \mathrm{a}+70^{\circ} \mathrm{C}$ e respectivas acurácias de $\pm 0,20^{\circ} \mathrm{C}, \pm$ 
$5,0 \%$ e $\pm 0,20{ }^{\circ} \mathrm{C}$. Os datallogers foram posicionados no interior da instalação e no centro de um globo negro, instalados fora e dentro da instalação, na altura dos animais (1,50 $\mathrm{m}$ acima do piso).

De posse dos dados das variáveis climáticas calculou-se o ITGU por meio da fórmula desenvolvida por BUFFINGTON et al. (1981), Equação 1:

$$
\text { ITGU = Tgn + 0,36Tpo + 41,5 }
$$

em que:

ITGU - Índice de Temperatura de Globo Negro e Umidade.

Tgn - Temperatura de globo negro, ${ }^{\circ} \mathrm{C}$.

Tpo - Temperatura do ponto de orvalho, ${ }^{\circ} \mathrm{C}$.

Os dados climáticos foram coletados diariamente, entretanto, foram organizados em forma de blocos, sendo primeiro Bloco ( $1^{\underline{a}}$ e $2^{\underline{a}}$ semana); segundo Bloco ( $3^{\underline{a}}$ e $4^{\underline{a}}$ semana); terceiro Bloco ( $5^{\underline{a}}$ e $6^{\underline{a}}$ semana);

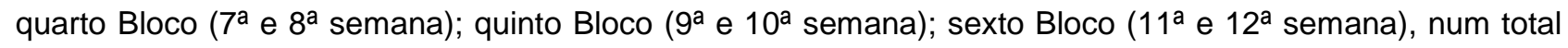
de seis blocos de análise experimental.

\section{Avaliação comportamental}

Para a avaliação comportamental os suínos foram monitorados diariamente. A avaliação comportamental foi do tipo instantânea no tempo de 5 segundos, realizada em cada tratamento de acordo com os seguintes comportamentos: comer (COM): consumindo ração no comedouro; em pé ou andando (EMP): em pé parado ou se locomovendo pela baia; deitado (DEI): deitado acordado ou dormindo; na lâmina d'água (LAM): animal na lâmina d'água em pé ou deitado, (comportamento observado apenas no tratamento 1). Foi o registrado do número de animais que estavam executando os comportamentos. As observações foram realizadas durante 5 horas no período da manhã P1 - (7:30 às 11:30 h) e 5 horas à tarde P2 - (13:30 às 17:30 h), com observações a cada 60 minutos, totalizando cinco repetições por período.

\section{Parâmetros fisiológico e de desempenho zootécnico}

Para a medição da temperatura superficial (TS) utilizou-se um termômetro digital infravermelho com mira laser, com faixa de temperatura: -50 a $380 \stackrel{\circ}{\circ}$, precisão: $\left(-50\right.$ a $\left.0{ }^{\circ} \mathrm{C}\right)+/-2{ }^{\circ} \mathrm{C}-(0$ a $380 \stackrel{\circ}{\circ})+/-1,5{ }^{\circ} \mathrm{C}$, que foi realizada na região dorso/lombar de 10 animais escolhidos aleatoriamente.

O desempenho zootécnico foi avaliado no início do experimento, com os animais distribuídos de forma uniforme nas respectivas baias e no fim do experimento considerou-se o peso médio dos animais (PMA) e o ganho de peso médio diário (GPMD), sendo os animais pesados individualmente a cada 15 dias, no fim de cada bloco, obtendo-se assim um total de sete pesagens. O peso inicial dos animais foi de 21,9 $\mathrm{kg}$ e $25,9 \mathrm{~kg}$, respectivamente, para os tratamentos 1 e 2 .

O PMA e o GPMD dos animais foram obtidos através de pesagens individuais $(\mathrm{kg})$ a cada tratamento, do seguinte modo: pesagem 1 ( 65 dias de idade): entrada no crescimento e terminação; pesagem 2 (80 dias de idade - bloco 1); pesagem 3 (95 dias de idade - bloco 2); pesagem 4 (110 dias de idade - bloco 3); pesagem 5 (125 dias de idade - bloco 4); pesagem 6 (140 dias de idade - bloco 5); pesagem 7 (155 dias de idade - bloco 6).

\section{Delineamento experimental e análise estatística}

O experimento foi conduzido segundo o esquema fatorial 2x2 (2 tratamentos: baia com e sem lamina d'água; 2 períodos: manhã e tarde), no delineamento em blocos casualizados (DBC), com seis blocos que foram estabelecidos a cada 2 semanas e 5 repetições por bloco (horários de avaliação).

As variáveis e os ITGU foram analisados por meio da estatística descritiva com a discussão das médias horárias para cada bloco. Os dados comportamentais e fisiológicos foram analisados por meio da análise de variância e as médias comparadas pelo teste de $\mathrm{F}$ e/ou Tukey adotando-se o nível de 1 e $5 \%$ de probabilidade. Para os dados de desempenho zootécnico utilizou-se a análise de regressão linear e logarítmica, respectivamente, e comparadas pelo teste $\mathrm{F}$. Os resultados foram interpretados por meio de análises de variância e regressão utilizando-se o Sistema de Análises Estatísticas e Genéticas (SAEG 2007).

\section{RESULTADOS E DISCUSSÃO}

Os suínos apresentam dificuldade de se adaptarem ao calor devido principalmente ao seu elevado metabolismo, a capa de tecido adiposo subcutâneo, seu sistema termorregulador pouco desenvolvido e limitada capacidade de perda de calor através da sudorese por apresentarem glândulas sudoríparas queratinizadas. Sendo, por essa razão, sensíveis ao calor quando adultos, o que dificulta sua adaptação aos trópicos (RODRIGUES et al. 2010).

Diante dos dados coletados em campo foi verificado que a temperatura do ar do ambiente externo foi 
superior à observada no interior do galpão (Figura 1). Independente do local avaliado a partir das 08:30 h a temperatura média do ar, principalmente no terceiro, quinto e sexto blocos, foram superiores ao valor máximo determinado para caracterizar o conforto térmico, em que a zona termoneutra encontra-se com limites desejados entre 10 a $27^{\circ} \mathrm{C}$, com a faixa de temperatura ideal para suínos em crescimento e terminação em torno de 21 e $18^{\circ} \mathrm{C}$, respectivamente (NATIONAL FARM ANIMAL CARE COUNCIL 2014).

Interior da instalação

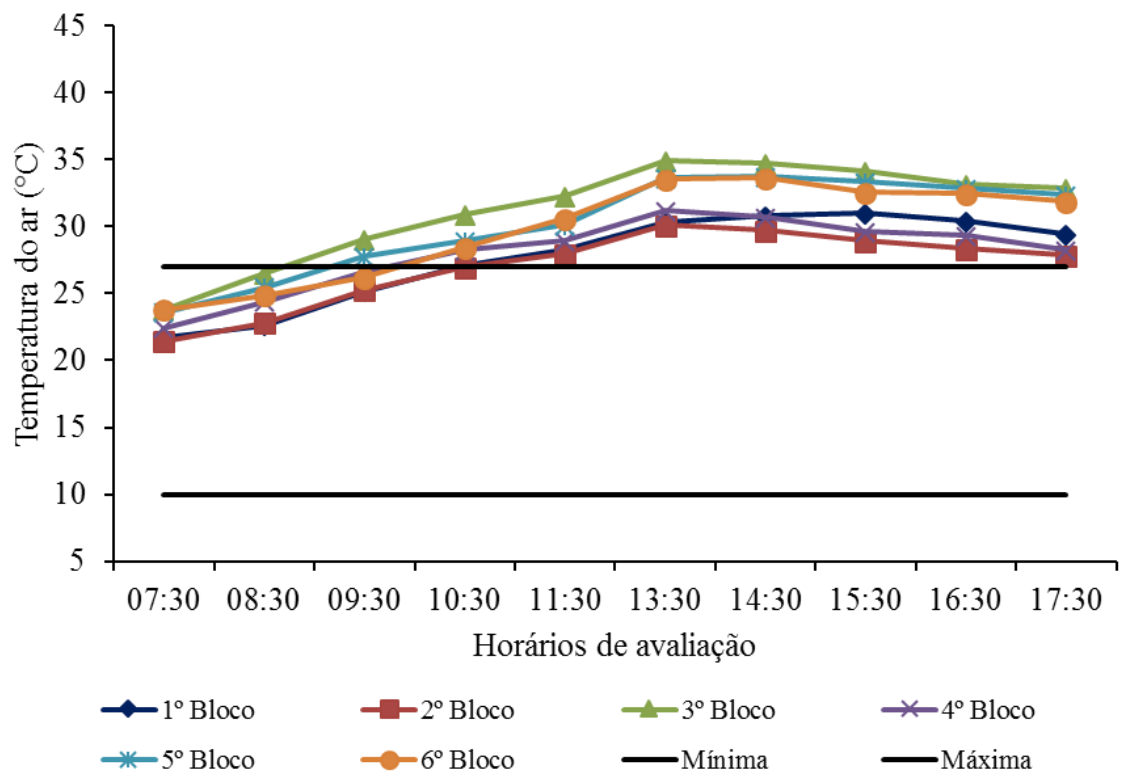

Área externa

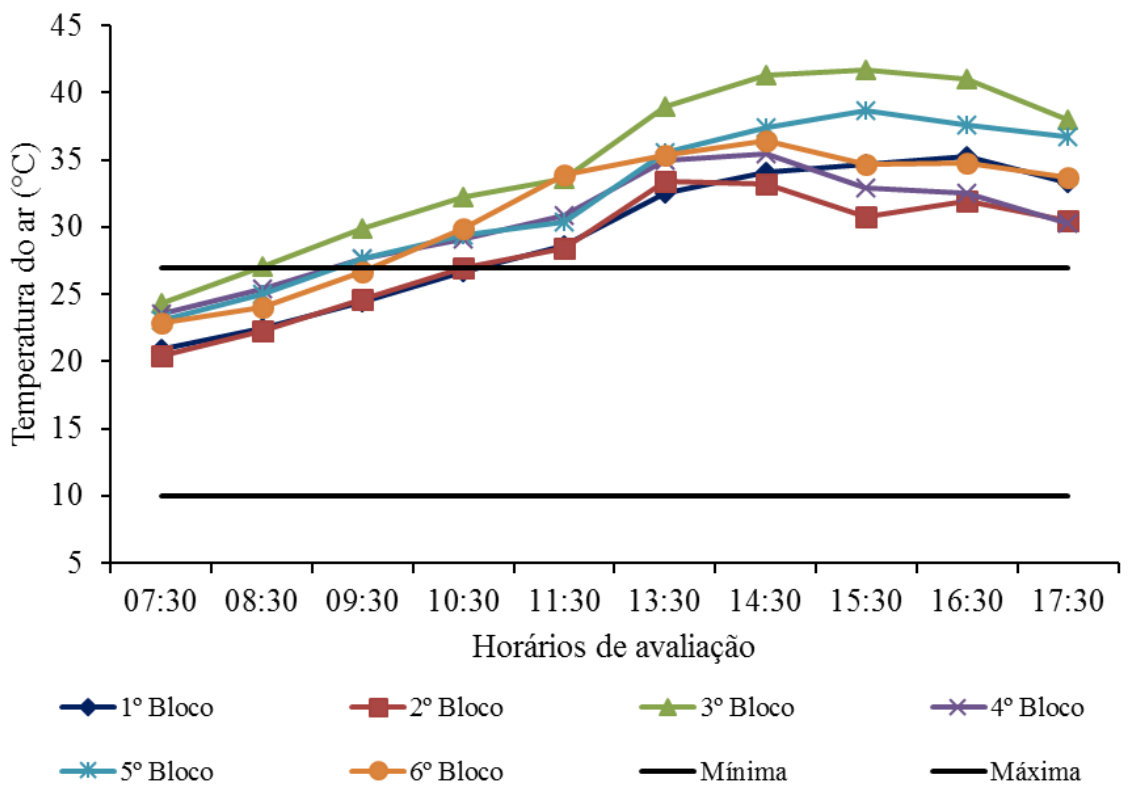

Figura 1. Valores médios de temperatura do ar coletados ao longo do dia durante os seis blocos avaliados. Figure 1. Average values of air temperature collected throughout the day during the six blocks evaluated.

Nos dois ambientes a temperatura do ar foi crescente ao longo do dia, atingindo $37^{\circ} \mathrm{C}$ no interior da instalação e $47^{\circ} \mathrm{C}$ na área externa às $13: 30 \mathrm{~h}$ no terceiro bloco, e com redução a partir das 16:00 h. A diferença de temperatura do ar existente entre os dois ambientes, embora ainda sendo superior a condição de conforto no interior da instalação, é justificada pelo amortecimento térmico favorecido pela tipologia da edificação composta por telha de barro, ventilação natural e artificial. Entretanto, ainda se faz necessário melhorias na edificação para auxiliar na redução da temperatura interna, como uso de nebulização e/ou aspersão e paisagismo circundante com uso de árvores para reduzir a incidência de radiação solar. De acordo com RENAUDEAU et al. (2011) a performance dos suínos piora com o aumento da temperatura e que os animais mais pesados perdem mais desempenho sob altas temperaturas que suínos leves. 
De acordo com os dados demonstrados na Figura 2 pode-se verificar que os valores de umidade relativa foram decrescentes dentro e fora da instalação. Suínos em terminação se encontram em um ambiente confortável quando o valor da UR varia entre 50\% e 70\% (SILVA 1999). Entretanto nos dois locais avaliados verificou-se que a partir das 9:30 h, principalmente no primeiro, segundo e terceiro blocos, a UR se manteve abaixo dos valores ideais, chegando a atingir $28 \%$ dentro do galpão e $16 \%$ fora do galpão ambos no terceiro bloco às 15:30 h, indicando uma situação de alerta podendo possivelmente vir a causar desconforto térmico.

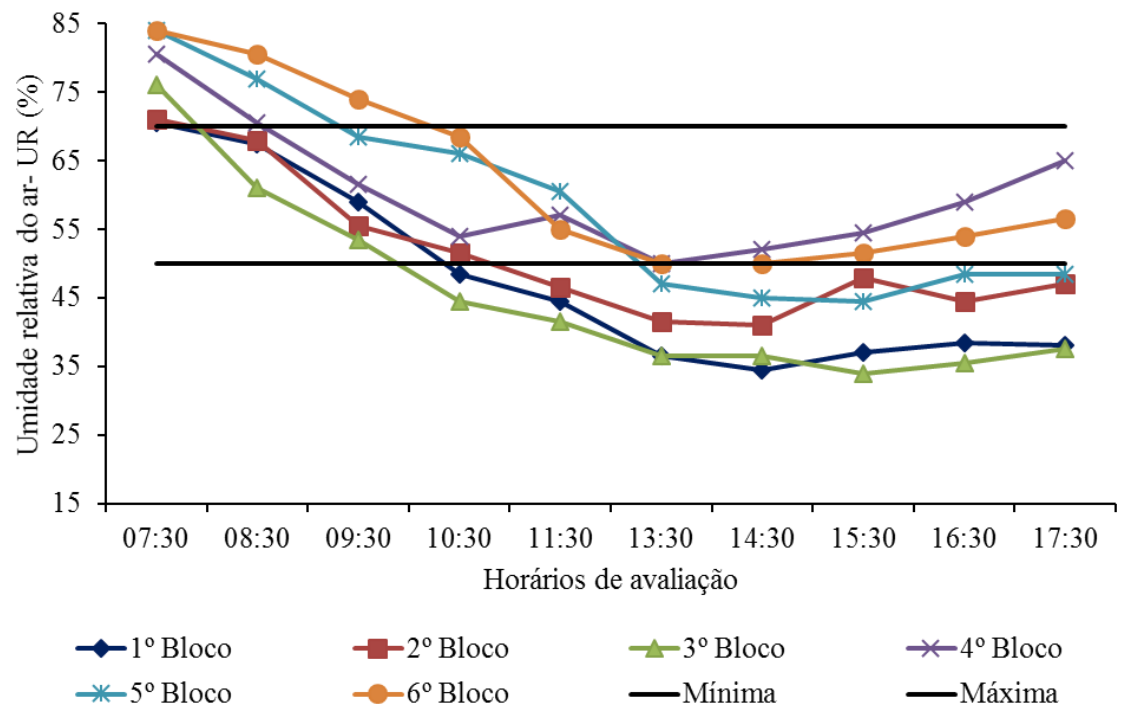

Área externa

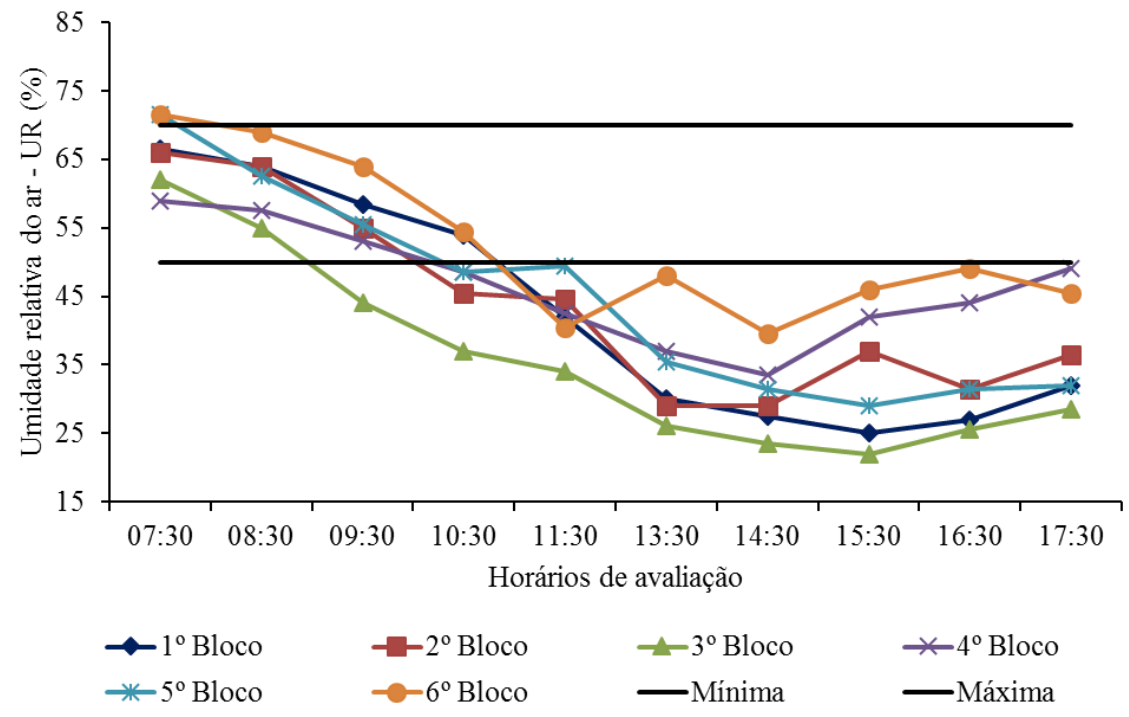

Figura 2. Valores médios de umidade relativa do ar coletados ao longo do dia durante os seis blocos avaliados.

Figure 2. Average values of air humidity collected throughout the day during the six blocks evaluated.

Os valores ideais de umidade relativa dificilmente são encontrados no semiárido mineiro na maior parte do dia.

Na Figura 3 verifica-se que os valores de ITGU dentro do galpão se mantiveram crescentes ao longo do dia e que a partir das 9:30 h o ITGU fora do galpão foi superior ao encontrado dentro do galpão se mantendo fora das condições de conforto, sendo os valores máximos encontrados no terceiro, quinto e sexto blocos. Entretanto, os menores valores de ITGU, foram verificados no segundo bloco. De acordo com BUFFINGTON et al. (1981), valores de ITGU até 74 definem conforto e acima de 84 é considerado sinal de emergência.

Os valores máximos de ITGU foram encontrados entre às 13:30 e 14:30 h, tanto no interior como fora 
do galpão. Embora os animais ficassem abrigados em ambiente provido de ventilação natural e artificial, às 07:30 h os valores de ITGU foram preocupantes, o que prova que é necessário realizar a adoção de modificadores ambientais a fim de impedir uma grande interferência do ambiente climático externo no interior da instalação. Segundo DIAS et al. (2015) o estresse térmico constitui um grave problema de bemestar animal, além de causar impactos negativos sobre a eficiência de produção.
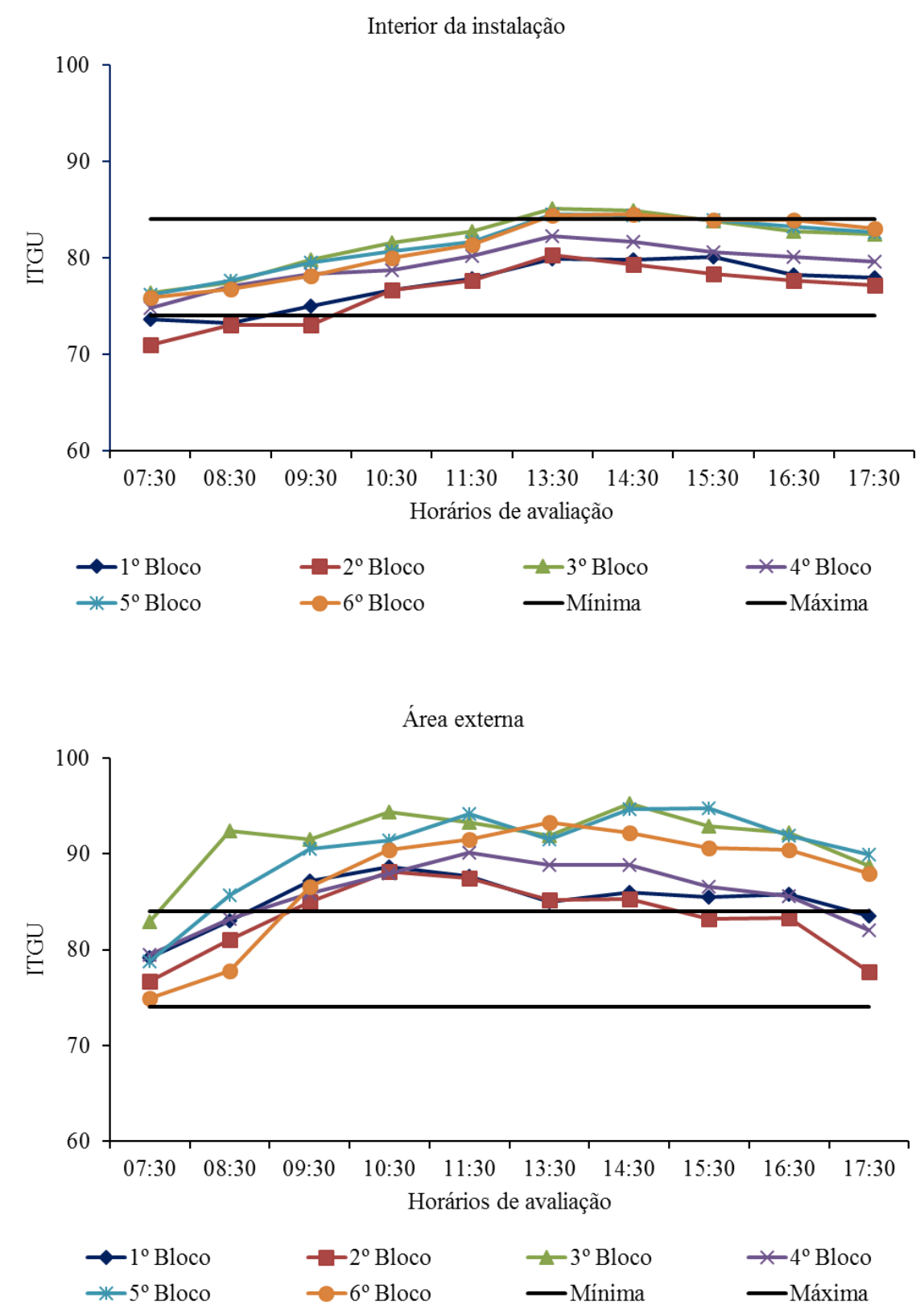

Figura 3. Valores médios de ITGU coletados ao longo do dia durante os seis blocos avaliados.

Figure 3. Mean values of ITGU collected throughout the day during the six blocks evaluated.

Por meio do resumo da análise de variância da avaliação do efeito dos tratamentos (lâmina d'água) e período (manhã e tarde) sobre os diferentes padrões comportamentais, para todas as características, verifica-se que todas as fontes foram significativas, com exceção para o comportamento EMP, com interação não significativa.

A partir dos resultados da análise de variância, todos os comportamentos observados, exceto COM, apresentaram diferença estatística significativa nos distintos tratamentos $(p<0,01)$, e todos os comportamentos, revelaram diferença estatística significativa para os períodos $(p<0,01)$. Além disso, as interações dos fatores, com exceção de comportamento EMP, foram significativas.

Os resultados relativos ao número médio de animais (\%) que expressaram o padrão comportamental comer (COM), deitar (DEI) e presença na lâmina d'água (LAM) encontram-se apresentados na Tabela 1. Verifica-se que os diferentes tratamentos e períodos foram capazes de influenciar os comportamentos COM e DEI $(p<0,05)$. O percentual médio do comportamento COM foi menor para o T1 (baia com lâmina d'água) 
em combinação ao período da manhã $(P 1)$, revelando diferença estatística significativa $(p<0,05)$ entre 0 período da tarde (P2). Isso leva a inferir que os suínos foram estimulados a consumir mais alimento no P2. Na Tabela 1 no P2 os animais do tratamento 1 (baia com lâmina d'água) comeram mais quando comparado ao tratamento 2 (baia sem lâmina d'água). Diante disso nota-se que o tratamento 1 proporcionou conforto aos animais nos períodos em que a temperatura esteve elevada, não afetando o consumo de ração pelos mesmos. Resultados obtidos por KIEFER et al. (2009) verificaram que suínos mantidos em ambientes com elevadas temperaturas permaneceram menos tempo comendo em relação àqueles mantidos sob ambiente de conforto térmico.

Tabela 1. Valores médios dos comportamentos dos suínos (\%) comer (COM), deitar (DEI), presença na lâmina d'água (LAM), para as respectivas combinações de tratamento e período durante a avaliação experimental.

Table 1. Mean values of the behaviors of the pigs (\%) eat (COM), lie down (DEI), presence in the water blade (LAM), for the respective Combinations of treatment and period during the experimental evaluation.

\begin{tabular}{|c|c|c|c|c|c|c|}
\hline \multirow{2}{*}{ Tratamento } & \multicolumn{2}{|c|}{$\mathrm{COM}$} & \multicolumn{2}{|c|}{ DEl } & \multicolumn{2}{|c|}{$\mathrm{LAM}^{*}$} \\
\hline & $\mathrm{P} 1$ & P2 & $\mathrm{P} 1$ & P2 & $\mathrm{P} 1$ & P2 \\
\hline $\mathrm{T} 1$ & $13,83^{A a}$ & $19,33^{B b}$ & $53,50^{A b}$ & $35,83^{A a}$ & $11,66^{a}$ & $16,33^{b}$ \\
\hline $\mathrm{T} 2$ & $16,33 \mathrm{Ba}$ & $17,00 \mathrm{Aa}$ & $59,33^{B a}$ & $50,17^{B b}$ & - & - \\
\hline
\end{tabular}

ॠMédias seguidas de mesma letra não diferem estatisticamente entre si, minúscula na linha e maiúscula na coluna, pelo teste de Tukey a $5 \%$ de probabilidade.

*LAM: Médias seguidas de mesma letra não diferem estatisticamente entre si; Significativo a $1 \%$ pelo teste F.

É importante ressaltar que a observação deste comportamento não indica necessariamente a ingestão de alimento, mas, em vez disso, simplesmente presença no comedouro. Ao se observar o percentual médio de animais no T2 (baia sem lâmina d'água) não foi possível observar diferença estatística significativa $(p>0,05)$ entre os períodos da manhã e tarde (P1 e P2). Os animais apresentaram o mesmo comportamento em ambos os períodos para o comportamento COM. Os melhores resultados encontrados foram para as combinações do T1 e P2, com maior porcentagem de animais comendo. Observa-se ainda, que a porcentagem média de animais no período da manhã $(P 1)$ foi menor para o $T 1$, com diferença estatística significativa $(p<0,05)$ com relação ao T2. No $P 2$ houve um percentual médio de animais menor no T2, onde também apresentaram diferença estatística significativa $(p<0,05)$ entre o T1. O maior número de animais expressando o comportamento COM no P2 é reflexo de que o $\mathrm{T} 1$ proporcionou maior conforto térmico aos animais, caracterizando um comportamento de maior consumo nesse período. A partir disso MOREIRA et al. (2003) enfatizam que há maior conforto térmico dos animais do tratamento com lâmina d'água, pois o limite de conforto para altas temperaturas é maior em suínos nessa fase.

Com relação ao comportamento DEI (Tabela 1), pode-se observar maior número de animais realizando este comportamento quando submetidos ao T1 durante o período da manhã (P1), com diferença estatística significativa $(p<0,05)$ em relação ao período da tarde $(P 2)$. Durante o período da manhã, os animais permaneciam deitados próximos uns aos outros na busca por realização de troca de calor, uma vez que as temperaturas nesse período eram mais baixas (Figura 1). Na Tabela 1, a porcentagem de animais deitados era menor no $\mathrm{T} 1$ no período da manhã $(\mathrm{P} 1)$, para que os animais se aquecessem pela manhã e à tarde para que os mesmos realizassem trocas de calor por condução com o piso. Portanto, MASSARI et al. (2015) relatam que para a mais efetiva troca de calor, o animal permanece mais tempo deitado, com o intuito de perder calor para o meio através do mecanismo de troca de calor por condução. Em condições de altas temperaturas ambientais os suínos estão mais sujeitos às sujidades no corpo, pois buscam deitar-se mais. Estima-se que para cada $1{ }^{\circ} \mathrm{C}$ a mais de temperatura ambiente, entre a faixa de 16 e $32{ }^{\circ} \mathrm{C}$, mais $0,58 \%$ dos animais passam a deitar utilizando mais as áreas maciças do piso, como as áreas das excreções (SPOOLDER et al. 2012). MEDEIROS et al. (2014) atribuiram o fato de suínos em fase de terminação permanecerem a maior parte do tempo deitados, por estarem maiores e com maior massa corporal, o que dificultaria a locomoção dos animais pelo ambiente.

$\mathrm{Na}$ Tabela 1 houve diferença estatística significativa $(p<0,05)$ entre os períodos no T2, apresentando maior percentual de animais realizando o comportamento DEI no P2. Analisando o P1, pode-se verificar que houve efeito significativo entre os tratamentos T1 e T2, tomando-se como base percentual média de animais 
expressando este comportamento $(p<0,05)$. Para o P2 houve também diferença estatística significativa entre os tratamentos T1 e T2. Nota-se que houve maior porcentagem de animais expressando o comportamento DEI no T2, em ambos os períodos, esse resultado pode ser explicado pela realização de troca de calor dos animais com o piso.

Já KIEFER et al. (2009) constataram que suínos em fase de crescimento permanecem mais tempo deitados, proporcionando melhor troca de calor com o meio e maior ganho de peso, uma vez que o incremento térmico implica diminuição da frequência do comportamento de comer.

Diante dos resultados obtidos na análise de variância observa-se que não houve interação significativa para o comportamento EMP. Na Tabela 2 verifica-se que existe diferença entre tratamentos e períodos, não havendo interação, apresentando efeito das variáveis dos fatores principais, sendo conclusivo pelo teste $\mathrm{F}$. O comportamento EMP mostrou-se diferente estatisticamente entre os tratamentos T1 e T2 e também para os períodos P1 e P2, com maior número de animais no T2 e P2. A maior porcentagem de animais em pé observada no período da tarde, principalmente no T2, mostra que os animais estavam em desconforto, o que leva a procura pela água para a realização de trocas de calor por convecção. KIEFER et al. (2010), relatam que animais mantidos sob estresse por calor permaneceram menos tempo na posição em pé em relação àqueles submetidos ao ambiente de conforto térmico. Vale lembrar que, os animais observados tinham acesso a objetos que serviam como enriquecimento ambiental (uma corrente) e como a curiosidade também é um comportamento natural dos suínos, eles buscavam durante a movimentação brincar, fuçar e desta forma, distrair. Problemas comportamentais surgem quando há a incompatibilidade entre o instinto suíno e o meio em que este habita (FOPPA et al. 2014).

Tabela 2. Efeito das variáveis dos fatores principais do comportamento dos suínos (\%), em pé (EMP), em função da Tratamento (T) e Período (P) durante a avaliação experimental.

Table 2. Effect of the variables of the main factors of the behavior of the pigs (\%), standing (EMP), as a function of the Treatment $(T)$ and Period $(P)$ during the experimental evaluation.

\begin{tabular}{ccccc}
\hline \multicolumn{3}{c}{ EMP } \\
\hline \multicolumn{3}{c}{ Tratamento } & & \multicolumn{2}{c}{ Período } \\
\cline { 1 - 2 } T2 & $27,41^{a}$ & & P1 & $24,58^{a}$ \\
& $30,41^{b}$ & & P2 & $33,25^{b}$ \\
\hline
\end{tabular}

Médias seguidas de mesma letra na coluna não diferem estatisticamente entre si; Significativo a $5 \%$ pelo teste $\mathrm{F}$.

Para o comportamento da presença na lâmina d'água (LAM), observou-se maior porcentagem dos animais realizando o comportamento LAM no período da tarde (Tabela 1), a partir desse resultado podemos inferir que no P2 a maior procura dos animais pela lâmina d'água ocorreu pelo fato do período da tarde apresentar maiores valores de temperatura com relação ao período da manhã, assim buscavam a água para se refrescar. BIAZZI et al. (2014) relatam que o uso de água rasa reduz comportamentos agonísticos, competição por bebedores, redução da sujeira e poeira. Nesta linha, JÄÄSKELÄINEN et al. (2014), avaliando a relação entre o bem-estar animal e a produtividade, concluíram que as ações tomadas a favor da melhoria do bem-estar aumentam a produtividade, repercutindo positivamente na economia da unidade, confirmando que a adoção de boas práticas de produção proporciona animais mais saudáveis e rebanhos mais produtivos.

Esse resultado pode estar relacionado à elevada temperatura do ar registrada durante o período da tarde, principalmente no terceiro bloco seguido do quinto e sexto blocos. A procura dos animais pela lâmina d'água expressa o comportamento natural dos mesmos, como fuçar e ao mesmo tempo umedecer o corpo e cabeça, aumentando assim a sensação de conforto térmico provocado pela água.

Com a utilização da lâmina d'água foi possível observar que a baia permaneceu mais limpa em relação àquela sem lâmina d'água, diminuindo assim o gasto de água na limpeza da baia. Além de fornecer conforto para os animais a lâmina d'água permite que os animais façam as necessidades fisiológicas na água. De acordo com PAIANO et al. (2007) suínos mantidos em baias de piso parcialmente ripado reduzem a frequência de consumo de ração nos horários de estresse por calor em relação aos das baias com lâmina d'água.

Na Tabela 3 verifica-se que as diferentes combinações têm influência na TS de suínos. Considerando o T1, observa-se que não houve diferença estatística entre os diferentes períodos avaliados, com valores médios da temperatura superficial semelhantes $(p>0,05)$. Já para o T2 foi possível observar diferença significativa entre P1 e P2, ocorrendo aumento da TS no P2. A TS aumentou significativamente $(p<0,05)$ na 
combinação T2 e P2 com relação às demais combinações. Esse fato é decorrente dos animais não poderem reduzir a temperatura corporal já que neste tratamento os animais não se beneficiaram da troca de calor proporcionada pela lâmina d'água. A temperatura superficial baixa é referente a temperatura à qual o animal desloca o fluxo de sangue para a superfície da pele para dissipar calor, contudo, a TS sofre variação quando os animais estão submetidos ao estresse climático (KIEFER et al. 2010, BROWN-BRANDL et al. 2012).

Tabela 3. Valores médios da temperatura superficial $\left(\mathrm{TS},{ }^{\circ} \mathrm{C}\right)$ dos suínos para as respectivas combinações de Tratamento e Período durante a avaliação experimental.

Table 3. Average values of the surface temperature $\left(T S,{ }^{\circ} \mathrm{C}\right)$ of the pigs for the respective combinations of Treatment and Period during the experimental evaluation.

\begin{tabular}{ccc}
\hline \multirow{2}{*}{ Tratamento } & \multicolumn{2}{c}{ TS } \\
\cline { 2 - 3 } & $\mathrm{P} 1$ & $\mathrm{P} 2$ \\
\hline T1 & $34,10^{\mathrm{Ba}}$ & $34,17^{\mathrm{Aa}}$ \\
$\mathrm{T} 2$ & $33,63^{\mathrm{Aa}}$ & $34,50^{\mathrm{Bb}}$ \\
\hline
\end{tabular}

Médias seguidas de mesma letra não diferem estatisticamente entre si, minúscula na linha e maiúscula na coluna, pelo teste de Tukey a $5 \%$ de probabilidade.

Considerando os períodos P1 e P2, observa-se que houve diferença $(p<0,05)$ entre os tratamentos T1 e T2. Os menores valores da TS foram encontrados no período da manhã (P1) em combinação com a baia sem lâmina d'água $(T 2)$, diferindo estatisticamente do $T 1(p<0,05)$. O resfriamento por aspersão de água ou por lâmina d'água reduzem o estresse por calor em suínos, uma vez que os animais expostos ao ambiente climatizado apresentam menor temperatura superficial que os animais do grupo controle (HUYNH et al. 2005).

Os dados descritos na Tabela 4 demostram que no terceiro bloco houve uma queda da porcentagem de ganho de peso nos dois tratamentos, apresentando valores de $10 \%$ para T1 e $12 \%$ para $\mathrm{T} 2$.

Tabela 4. Desempenho de suínos na fase de crescimento e terminação nos diferentes tratamentos.

Table 4. Performance of pigs in the growth and finishing phase in the different treatments.

\begin{tabular}{|c|c|c|c|c|c|c|c|}
\hline \multirow[t]{2}{*}{ Bloco } & \multirow[b]{2}{*}{$\begin{array}{l}\text { Idade } \\
\text { (dias) }\end{array}$} & \multicolumn{2}{|c|}{ Peso do animal $(\mathrm{kg})$} & \multicolumn{2}{|c|}{$\begin{array}{l}\text { Ganho de peso médio } \\
\text { diário por bloco }\left(\mathrm{kg} \mathrm{dia}^{-1}\right)\end{array}$} & \multicolumn{2}{|c|}{$\%$ de ganho de peso $(\mathrm{kg})$} \\
\hline & & T1 & $\mathrm{T} 2$ & T1 & $\mathrm{T} 2$ & $\mathrm{~T} 1$ & $\mathrm{~T} 2$ \\
\hline Inicial & 65 & 21,90 & 25,90 & 0 & 0 & & \\
\hline 1 & 80 & 31,20 & 32,34 & 0,6207 & 0,4288 & 15 & 10 \\
\hline 2 & 95 & 40,02 & 44,35 & 0,5883 & 0,8011 & 15 & 19 \\
\hline 3 & 110 & 46,20 & 51,91 & 0,4133 & 0,5035 & 10 & 12 \\
\hline 4 & 125 & 58,75 & 65,30 & 0,8357 & 0,8930 & 21 & 21 \\
\hline 5 & 140 & 69,95 & 77,76 & 0,7463 & 0,8309 & 18 & 19 \\
\hline 6 & 155 & 82,69 & 90,28 & 0,8497 & 0,8344 & 21 & 19 \\
\hline Total & & & & 4,0540 & 4,2916 & 100 & 100 \\
\hline
\end{tabular}

Devido ao manejo adotado na granja, o peso inicial dos animais do T1 foi menor quando comparado com o T2. Esse fato pode ter interferido na redução do ganho de peso do animal, não sendo o fator lâmina d'água um determinante para auxiliar no ganho de peso. Embora a lâmina d'água não tenha influenciado no ganho de peso por animal e bloco, proporcionou melhores condições de conforto por permitir aos animais em expressar seu comportamento natural, como pode-se observar nos resultados de comportamento.

Os resultados da análise de regressão indicaram efeito significativo $(p<0,01)$, para o comportamento do ganho de peso médio diário (GPMD) nos diferentes tratamentos em função dos blocos (Figura 4). Observa-se que o ganho de peso não é linear durante o período de avaliação, sendo que durante o bloco 1 , de 65 até 80 dias de idade, ocorreu um ganho linear e depois ocorre a estabilização do ganho de peso médio diário dos animais.

Considerando o GPMD no início do experimento, aos 80 dias (bloco 1), verifica-se que o T1 obteve melhores resultados quando comparado ao T2. Apesar do T2 apresentar melhores valores de GPMD 
observa-se que entre os tratamentos é semelhante ao longo dos dias de avaliação. A criação de suínos na fase de crescimento-terminação, em baias com lâmina d'água ou em baias de piso compacto, resulta em respostas de desempenho semelhantes. Entretanto, para a fase de crescimento, as baias com lâmina d'água proporcionam maior consumo de ração e ganho de peso.

Os maiores valores de GPMD foram observados os 155 e 125 dias para o T1 e T2, respectivamente. De acordo com DIAS et al. (2011), o ganho de peso médio diário esperado para a fase de crescimento e terminação encontra-se em torno de 0,850 kg. Diferente do encontrado neste trabalho VICARI JUNIOR et al. (2016), verificaram que em machos castrados o ganho de peso diário foi de $1,0109 \mathrm{~kg} \mathrm{dia}^{-1}$ para suínos em crescimento e terminação. A diferença entre os trabalhos pode ser explicada pela temperatura do ar, neste experimento que se encontrava acima da zona de conforto térmico na maior parte do tempo. Entretanto, em alguns blocos, valores próximos de GPMD foram encontrados por LEAL et al. (2015) de 0,87 $\mathrm{kg} \mathrm{dia}^{-1}$.

Tratamento 1

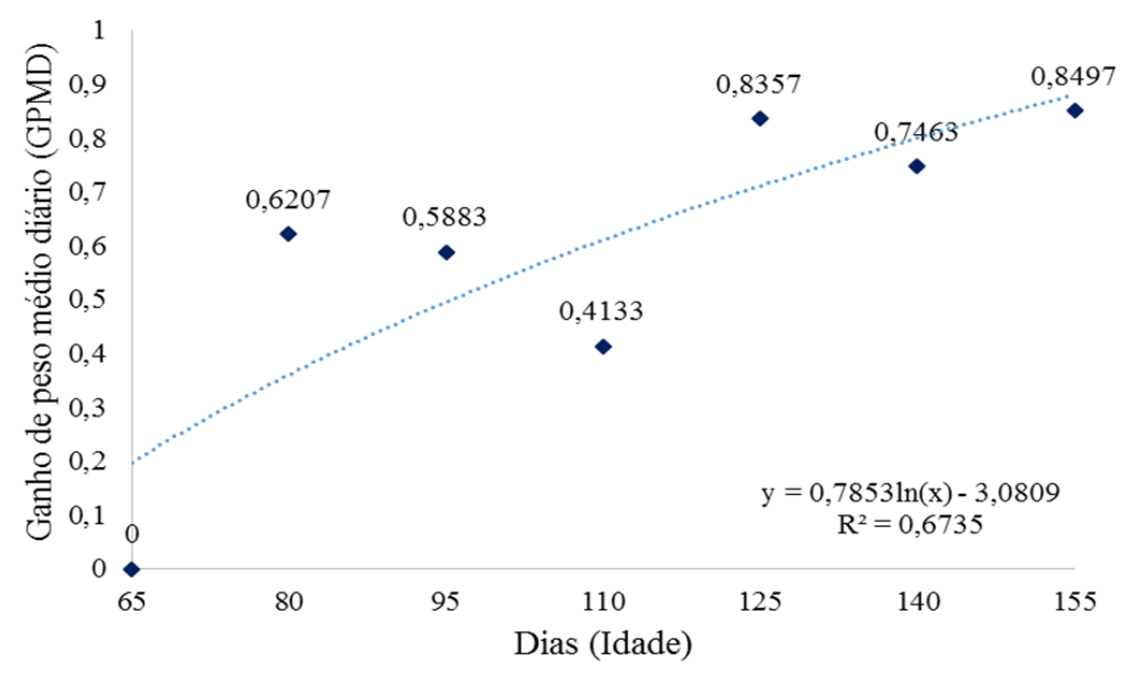

Tratamento 2

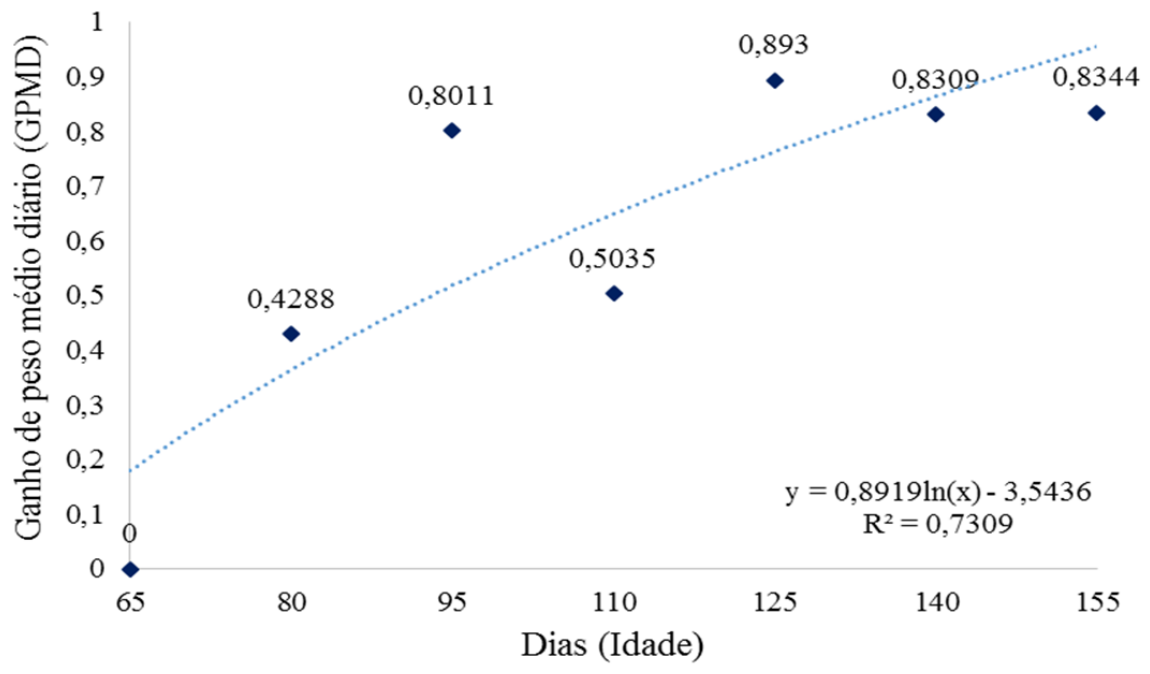

Figura 4. Análise de regressão do ganho de peso médio diário (GPMD) de suínos na fase de crescimento e terminação submetidos a baia com lâmina d'água (Tratamento 1) e baia sem lâmina d'água (Tratamento 2).

Figure 4. Regression analysis of the daily average weight gain (GPMD) of pigs in the growth and termination phase submitted to the bay with water blade (Treatment 1) and the bay without water blade (Treatment 2).

Confrontando os dados de GPMD e variáveis ambientais (Figura 4), foi observada uma queda do GPMD aos 110 dias de idade (bloco 3). Esse resultado pode ser reflexo dos maiores valores das variáveis climáticas e ITGU encontrados no terceiro bloco. A partir desses resultados pode-se inferir que o GPMD é inversamente proporcional ao aumento da temperatura do ar ao longo dos blocos de avaliação, mostrando 
que o ganho de peso é reduzido quando os animais se encontram em situações de desconforto térmico influenciando diretamente no seu desempenho. Resultados similares foram encontrados por KIEFER et al. (2010), que verificaram que o ambiente térmico influenciou o ganho de peso diário, e os animais mantidos sob estresse por calor apresentaram valores de $0,53 \mathrm{~kg} \mathrm{dia}^{-1}$, enquanto àqueles submetidos ao ambiente de conforto térmico obtiveram melhores valores de ganho de peso $0,93 \mathrm{~kg} \mathrm{dia}^{-1}$.

$\mathrm{Na}$ análise de regressão, também não foi observada significância para o peso médio dos animais. $\mathrm{Na}$ Figura 5 observa-se que o peso médio dos animais é crescente a partir dos 65 dias de idade, sendo que com o passar dos dias o animal tem um ganho médio significativo de 0,663 e $0,726 \mathrm{~kg} \mathrm{dia}^{-1}$, respectivamente. Nota-se que existe o efeito do dia no peso dos animais, sendo os valores encontrados diferente de zero.

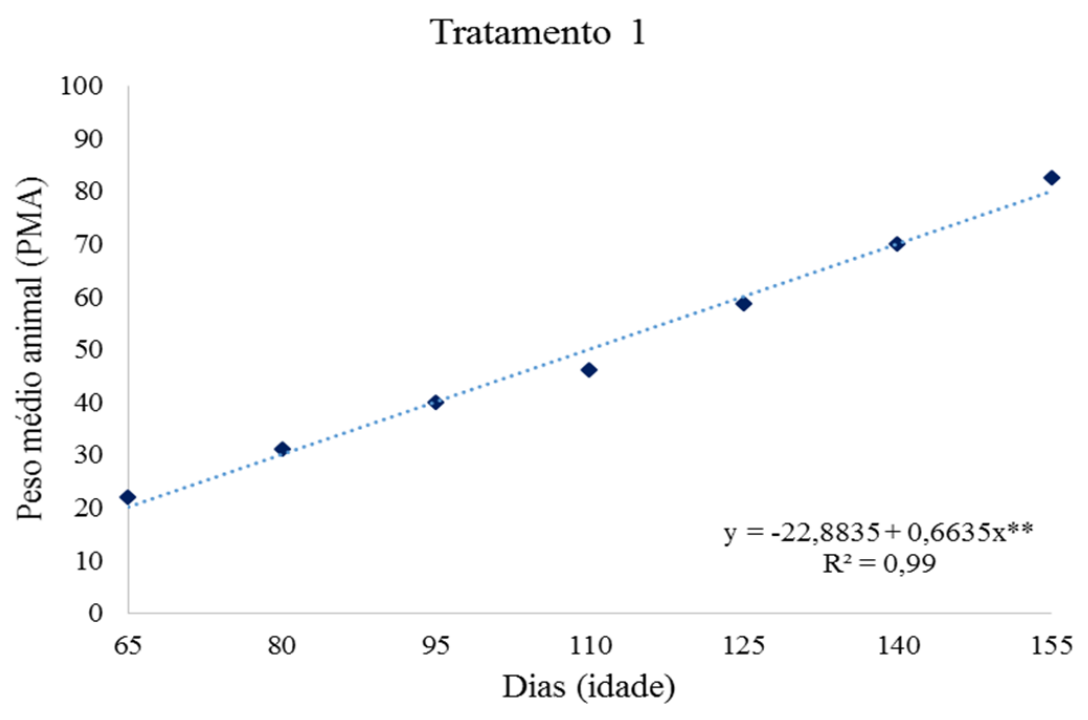

Tratamento 2

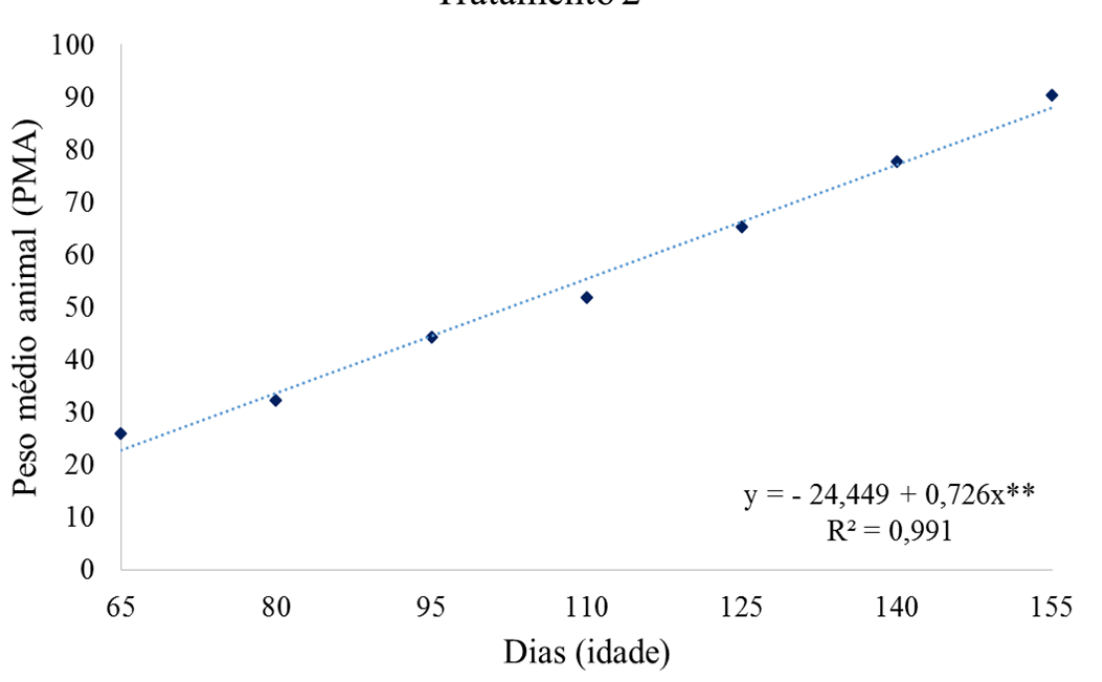

Figura 5. Análise de regressão do peso médio animal (PMA) de suínos na fase de crescimento e terminação submetidos a baia com lâmina d'água (Tratamento 1) e baia sem lâmina d'água (Tratamento 2). ${ }^{*}$ Significativo ao nível de $1 \%$ de probabilidade pelo teste $\mathrm{F}$.

Figure 5. Regression analysis of the mean animal weight (PMA) of pigs in the growth and termination phase submitted to the bay with water blade (Treatment 1) and the bay without water blade (Treatment 2). ** Significant at the $1 \%$ probability level by the $F$ test.

As equações de regressão para o peso médio dos animais indicam efeito significativo $(p<0,01)$ ao longo do experimento. Os resultados podem ser explicados por meio da equação: (PMA $=-22,8835+$ $0,66351 \mathrm{DIA})$ e (PMA $=-24,449+0,726 \mathrm{DIA})$.

Criar e produzir suínos em região semiárida, caracterizada por apresentar elevadas temperaturas, exige por parte do produtor cuidados criteriosos com relação ao material utilizado na edificação das granjas, bem como, investimento adequado em sistemas de ventilação (natural e artificial) e nebulização a fim de atender de forma satisfatória aos quesitos de bem-estar e conforto térmico animal. 


\section{CONCLUSÃO}

A criação de suínos na fase de crescimento-terminação em baias com lâmina d'água ou em baias de piso de concreto resulta em diferentes respostas comportamentais, sendo o comportamento LAM mais expressivo no período da tarde. O período de avaliação mostrou influenciar na TS e em temperaturas elevadas os animais apresentam menor GPMD.

\section{AGRADECIMENTOS}

À Granja Araújo, UNIMONTES e a FAPEMIG.

\section{REFERÊNCIAS}

BERTON MP. 2013. Ambiente controlado e não controlado no desempenho, comportamento e características da carcaça de suínos. Dissertação (Mestrado em Zootecnia). Jaboticabal: UNESP. 53p.

BIAZZI HM et al. 2014. Behavioral, thermoregulatory, and operational aspects of shallow pool pens used in gilts production. Semina: Ciências Agrárias 35: 3439-3448.

BROWN-BRANDL TM et al. 2012. Determining Heat Tolerance in Finishing Pigs Using Thermal Imaging. In: INTERNATIONAL LIVESTOCK ENVIRONMENT SYMPOSIUM, 9. Proceedings... Valencia: ASABE. p. 1-8.

BUFFINGTON SC et al. 1981. Black-Globe-Humidity Index (BGHI) as comfort equations for dairy cows. Transactions of the ASAE 24: 711-714.

CARVALHO LE et al. 2004. Utilização da nebulização e ventilação forçada sobre o desempenho e a temperatura da pele de suínos na fase de terminação. Revista Brasileira de Zootecnia 33: 1486-1494.

DIAS AC et al. 2011. Manual brasileiro de boas práticas agropecuárias na produção de suínos. Concórdia: Embrapa Suínos e Aves. 140p.

DIAS CP et al. 2015. Efeitos do alojamento no bem-estar de suínos em fase de crescimento e terminação. Ciência Animal 25: 76-92.

FOPPA L et al. 2014. Enriquecimento ambiental e comportamento de suínos: revisão. Brazilian Journal of Biosystems Engineering 8: 1-7.

GONÇALVES RG \& PALMEIRA EM 2006. Suinocultura Brasileira. Observatorio de la Economía Latinoamericana. Revista Académica de Economia, no. 71. Disponível em: <http://www.eumed.net/cursecon/ecolat/br/06/rgg.pdf>. Acesso em: 19 fev. 2014.

HUYNH TTT et al. 2005. Effects of increasing temperatures on physiological changes in pigs at different relative humidities. Journal of Animal Science 83: 1385-1396.

JÄÄSKELÄINEN T et al. 2014. Relationships between pig welfare, productivity and farmer disposition. Animal Welfare 23: $435-443$.

KIEFER C et al. 2009. Resposta de suínos em crescimento mantidos em diferentes temperaturas. Archivos de Zootecnia 58: 55-64.

KIEFER C et al. 2010. Respostas de suínos em terminação mantidos em diferentes ambientes térmicos. Revista Brasileira de Saúde e Produção Animal 11: 496-504.

LEAL RS et al. 2015. Desempenho e rendimento de carcaça de suínos na fase de terminação, recebendo dietas com diferentes níveis de ractopamina. Revista Brasileira de Saúde e Produção Animal 16: 582-590.

MASSARI JM et al. 2015. Características comportamentais de suínos em crescimento e terminação em sistema "Wean to finish". Engenharia Agrícola 35: 646-656.

MEDEIROS BBL et al. 2014. Uso da geoestatística na avaliação de variáveis ambientais em galpão de suínos criados em sistema "wean to finish" na fase de terminação. Engenharia Agrícola 34: 800-811.

MOREIRA I et al. 2003. Desempenho e características de carcaça de suínos (33 - $84 \mathrm{~kg}$ ) criados em baias de piso compacto ou com lâmina d'água. Revista Brasileira de Zootecnia 32: 132-139.

NATIONAL FARM ANIMAL CARE COUNCIL. 2014. Code of practice for the care and handling of pigs. Code of practice. $\underline{78} \mathrm{p}$.

PAIANO D et al. 2007. Comportamento de suínos alojados em baias de piso parcialmente ripado ou com lâmina d'água. Acta Scientiarum. Animal Sciences 29: 345-351.

PANDORFI H et al. 2008. Conforto térmico para matrizes suínas em fase de gestação, alojadas em baias individuais e coletivas. Revista Brasileira de Engenharia Agrícola e Ambiental 12: 326-332.

RENAUDEAU D et al. 2011. A meta-analysis of the effects of high ambient temperature on growth performance of growing-finishing pigs. Journal of Animal Science 89: 2220-2230.

RODRIGUES NEB et al. 2010. Adaptações fisiológicas de Suínos sob estresse térmico. Revista Eletrônica Nutritime 7: 1197-1211.

SALES FAL et al. 2011. Monitoramento ambiental do perfil horizontal de um galpão para suínos, na fase de gestação, utilizando zootecnia de precisão. Revista Científica Produção Animal 13: 7-12.

SILVA IJO. 1999. Qualidade do ambiente e instalações na produção industrial de suínos. In: Seminário internacional de suinocultura, 4. Anais... Piracicaba: ESALQ. p. 108-121.

SOUZA BB et al. 2010. Efeito do ambiente sobre as respostas fisiológicas de caprinos saanen e mestiços $1 / 2$ saanen $+1 / 2$ boer no semiárido Paraibano. Agropecuária Científica no Semiárido 6: 47-51. 
SPOOLDER HAM et al. 2012. Effect of increasing temperature on space requirements of group housed finishing pigs. Applied Animal Behaviour Science 138: 229-239.

SAEG. 2007. Sistema para Análises Estatísticas, Versão 9.1: Fundação Arthur Bernardes - UFV - Viçosa.

VICARI JUNIOR D et al. 2016. Melhoria de índices zootécnicos em suínos com imunocastração. Unoesc \& Ciência ACET 7: 89-94. 